\title{
A Conceptual Design of Energy Harvest from Roadside Trees of a Highway
}

\author{
Minhajul Haque Minar ${ }^{1}$, Md. Shawon Rana ${ }^{1}$, Sahriar Rahman Tanvir ${ }^{1}$, Dewan Hasan Ahmed ${ }^{1^{*}}$
}

${ }^{1}$ Department of Mechanical and Production Engineering, Ahsanullah University of Science and Technology, Dhaka, BANGLADESH

*Corresponding Author: dhahmed@hotmail.com

Citation: Minar, M. H., Rana, Md. S., Tanvir, S. R., \& Ahmed, D. H. (2020). A Conceptual Design of Energy Harvest from Roadside Trees of a Highway. European Journal of Sustainable Development Research, 4(1), em0106. https://doi.org/10.29333/ejosdr/6264

\section{ARTICLE INFO}

Received: 22 Aug. 2019

Revised: 14 Oct. 2019

Accepted: 17 Oct. 2019

\begin{abstract}
An experimental setup is constructed to harvest energy from wind by means of oscillating of a body, structure or even trees. A vertical stem which can oscillate or bend is connected with a rack and pinion and finally pinion is connected with generator to harvest the electrical energy. Once the force is applied on the top of the stem, the connecting wire pulls the rack and pinion is in rotary motion and generates the power. The experiments are carried out for both applied static force and wind assist dynamic force. The experimental results show that the forces exerted on the stem are very much influenced by the stem height, the rack length for power generation. The results from wind assist experiments reveals that the sail size and the materials of both stem and sails play vital role on power generation. The constructed setup shows a good prospect on power generation from wind specially the places like highways, urban areas or any other places where the tree or any other object or structure oscillate.
\end{abstract}

Keywords: energy harvesting, oscillating body, wind energy, flexural strength, flexible body

\section{INTRODUCTION}

Now-a-days, there are so many technologies that are used for energy harvesting. Some of them are - Piezo-electric energy harvesting, Hydro power (Deane et al. 2010), Wind power (Howell et al., 2010; Lewis, 2007), Solar cells (https://www.nrel.gov/solar/, http://energy.mit.edu/research/) RF energy harvesting (https://www.rfpage.com/, https://www.arrow.com/en/research-and-events/) and so on. Researchers and scientists made a huge investment in recent years for harvesting energies. Due to some drawbacks and high production cost, everyone is trying to replace the conventional energy production with the renewable energy. Hydro power is one of the largest renewable energy sources in the world. The power generation by hydro power is increased significantly for past 50-60 years. Deane et al. (2010), Han et al. (2014), Molarius et al. (2010), Lehner et al. (2005), Kumar and Katoch (2014) had done some empirical research about power generation by hydro power technology. But the major drawback of hydropower is that the constructed damsare permanent which cannot be removed. In addition, the local resident needs to relocate for hydropower. These types of huge projects can damage fish population and also can impact water quality and flow. Meanwhile, the production of solar power technologies is developed a lot in industrial countries like Japan \& Germany for last few decades. Some research institutes like NREL (National Renewable Energy Laboratory) and MIT Energy Initiative are working very hard to develop new design, materials, manufacturing process and also minimize environmental impacts. Though solar energy has become a trending topic, it has been widely criticized for being expensive as well as for its weather dependency. Moreover, it requires a lot of spaces. In fact, to produce more electricity, it needs more solar panels to collect as much sunlight as possible. So these reasons discourage people to use the solar system. However, RF energy harvesting has no problem like solar cells. But dependency on external sources limits its usage all over the world. It looks so simple at first glance. The reduction of the system efficiency over the time is another limitation of this technology. On the other hand, piezo-electric energy harvesting is a hot topic over the years. Li et al. (2014), Mak et al. (2012), Qiu and Ji (2011), Xu et al. (2012) and many researchers had given much efforts about Piezo-electric energy harvesting to generate power. The possible disadvantages of using piezo-electric energy harvesting technology are very small amount of power generated \& cannot be used for truly static measurements. The technology uses to harness the power of wind has progressed a lot over the last few years. Now each wind turbine could generate much electricity as a conventional power plant does. Researchers like Strom et al. (2017), Howell et al. (2010), Lewis (2007) had tried to take this technology to another level. But there are some limitations of wind turbines like turbines are noisy, threatening to Wildlife, higher installation Costs and so on.

Despite of different disadvantages of different renewable sources, the mankind is still hoping for upgrading and inventing new energy sources. There are few works are found in literature related to energy harvest from tree. McGarry and Knight (2011) 
investigated to generate power from the tree movement. They showed that the movement of the tree can lift the weight and hence produce the power. Later in 2012, McGarry and Knight (2012) further reported that a $6 \mathrm{~m}$ tall tree can drive the electromagnetic generator and that recharge a nickel metal hydride battery. They experimentally showed that the electromagnetic drag may produce up to $12 \mathrm{~N}$ for the particular tree and setup. Souza et al. (2016) reported that the energy can harvest from the tree trunk as the tree trunk has different isothermal zone and can generate electrical power by Peltier cell. Xu and Feng (2012) were interested in the electrical potential difference (EPD) of a tree. Therefore, they investigated three kinds of trees and recorded the bioelectric current and voltage difference for a year. They reported that there is a voltage difference and electric current in the trees and the amount of energy is influenced by temperature, humidity.

There are few more efforts can be found in literature to harness the energy from tree leaves like 'leaf generator' from PZT nanofiber (Zhang et al., 2014), plastic leaves containing polyvinylidene fluoride (PVDF) (Han et al., 2010), piezo-leaf with a "vertical flapping stalk" (Li et al., 2014). However, McCloskey et al. (2017) investigated the vertical flapping stalk with piezo-electric leave to harvest the energy and reported that the piezo-electric botanic mimic may not be good to generate mid-range of power.

Wind energy can be used to generate electricity in small scale for the daily life as well. For example, the divider in the highway or beside the highway there are lots of wind energy due to the rapid movement of the vehicles. In fact, once the vehicles move with a high velocity, leave the number of vortices which contain much energy. Quinn et al. (2001) showed that the road signs and pedestrian barrier experience high wind force due to the vehicle movements. With the general experience, the small trees in the divider or beside the highway oscillate or swing randomly. These oscillations or swings of the small tree are due to wind energy and can be converted to electrical energy. There can be found numerous examples of oscillation or swing to the body or structure in different situation and location for the wind energy where the wind energy is being wasted. In fact, there is a good potential of harvesting energy from wind at high rise building areas (Glumac et al., 2018). In fact, build spacing and high rise buildings in the urban area cause to flow strong wind at base (pedestrian level at the ground) and also at the top of the buildings (Blocken and Stathopoulos, 2013; Blocken et al., 2016; Ricci et al., 2018; Sheng et al., 2018; Stathopoulos, 1985; Zheng et al., 2018).

The main concept is to find a way to use or store this wasted wind energy. Therefore, a setup is constructed with simple rack and pinion mechanism to convert the wind energy to mechanical energy and hence the electrical energy. To extract more power the experiments are carried out with different flexible stem, rack movement or displacement, placing a sail at the top of the stem, sail size, sail materials etc.

From the literature it has been found that the researchers put much effort on harvesting energy by many means like piezoelectric materials, RF, micro hydropower etc. Most of the efforts are limited to certain conditions or accessibility of the sources. Most of the energy harvesting devices (low scale output) is generally constructed with the mechanism of electromagnetic, piezoelectric or triboelectric (Khalid et al., 2019) and faces lots of problems in installation, performance, efficiency, durability and robustness (Xu et al., 2019; Zhou et al., 2019). Here, it has been tried to present a conceptual design to harvest energy from wind within our daily activities. In fact, the wind is forced to flow once a vehicle drives on the highway. Usually, there are always vortices behind the vehicle and become a gust wind once the vehicle speed increases specially for the heavy vehicles. Indeed, the efforts are made to introduce a new conceptual design which is cost efficient, very minimal maintenance cost, environment friendly, doesn't require larger space as well as the mechanism is very easy and simple. Therefore, the concept of energy harvest on the highways may open huge prospects to meet the energy demand as there are thousands of kilometer roads around the world and millions of vehicles move each day.

\section{EXPERIMENTAL SET UP}

Tree, bamboo or any other thing which can oscillate or swing due to wind flow is replaced as flexible stem. A T-joint is placed at the top of the stem and a sail is mounted on the T-joint. A wire is tied at the top portion of the sail and other end of the wire is connected to a rack which is placed at the base. Figure 1 shows the SolidWork design of this experimental setup. Two sets of rack and pinion with generator are placed on the two opposite sides of the setup. The photographic view of the setup with labeling is also shown in Figure 2. It should mention here that the stem is placed in a stem holder, which is 1 inch $(2.5 \mathrm{~cm})$ height and larger than stem diameter. Once the force applied or wind flows over the sail, the stem bend and therefore the wire which is at the upstream position of the wind flow or applied force creates a tension force to pull the rack. A pinion is placed at a particular position and the due to the movement of the rack, the pinion rotates which is meshed with a generator to produce the electricity. The present constructed setup is $5 \mathrm{ft}(153 \mathrm{~cm})$ in length and $3 \mathrm{ft}(92 \mathrm{~cm})$ in height. The major parts or components for the setup are rack, pinion with lock bearing, nylon roller, generator and so on. The lock bearing is used to allow the rotation in one direction. However, nylon roller guides the linear motion of the rack and helps the rack to move in the right direction and also prevents the lifting of the rack from its position. 


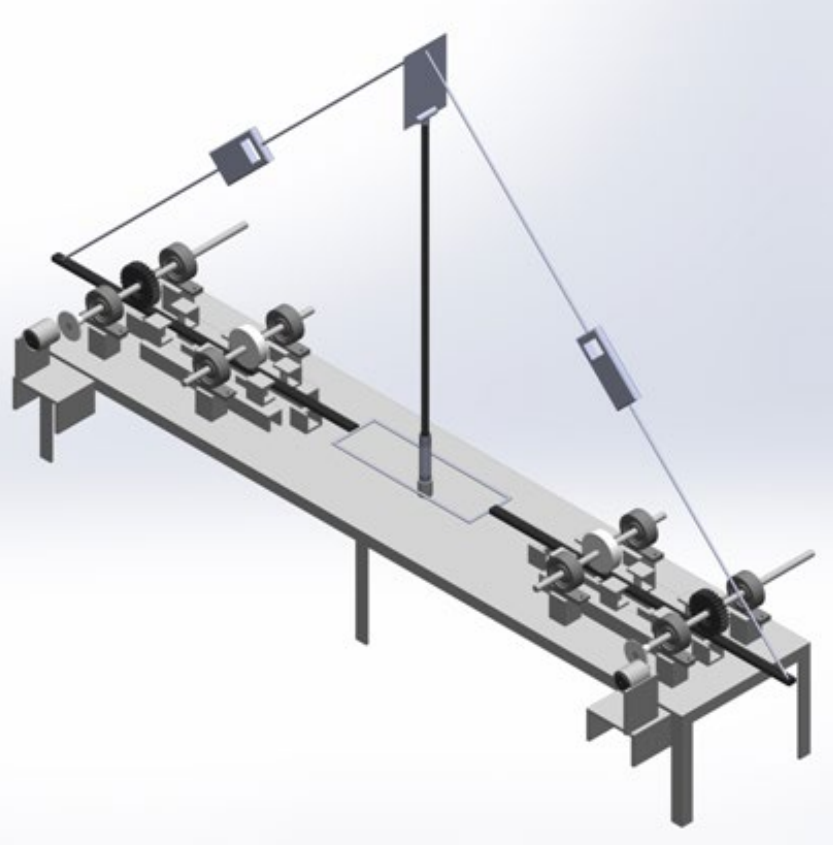

Figure 1. Schematic view of the experimental setup

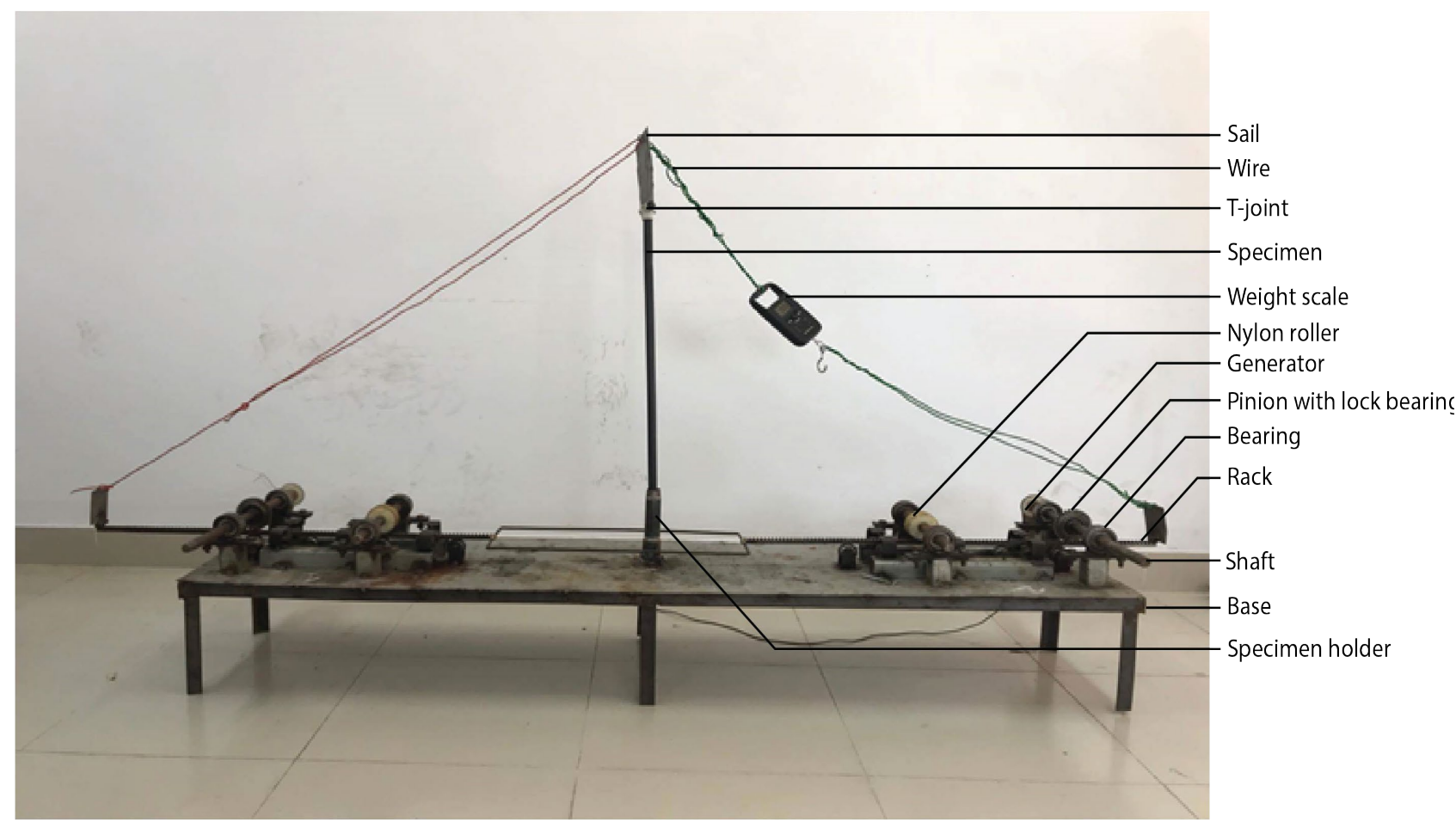

Figure 2. Photographic view of the experimental setup

\section{WORKING PROCEDURE}

After constructing the setup, a force is applied on the sail either by manually or wind flow. A spring guage is connected with the sail for manual applied force (sail is made of mild steel plate 4 inch $\times 6$ inch or approx. $10 \mathrm{~cm} \times 15 \mathrm{~cm}$ )) or wind flow to make sufficient pressure on sail to bend the stem. Once the stem bends in one direction, the wire on the opposite side is in tension force and hence the rack moves and pinion rotates in one direction. With the rotation of the pinion the shaft of the generator produces electricity. Two multimeters (VICTOR $86 \mathrm{~B}, \pm 0.5 \% \sim 1.0 \%$ accuracy)) are used to measure voltage and ampere and calculate the power in watt. 
For manual applied force, different types of specimen like PVC pipe, acrylic, MS rod and tree stem are used to obtain the power. The experimental study continues with different height of the stem for different stem material and also for different rack length. As the two sets of rack-pinion and DC generator are placed on two sides of the setup, the experiments are continued for both side as Side-1 and Side-2. Similar procedures are also applied for wind flow cases where the sail is changed with different materials, areas and also the stems with different heights for different air velocities. It should mention here that anemometer (CEM DT-618, $\pm 3 \% \pm 0.1$ ) and tachometer with $0.02 \%$ accuracy (VA8030 of aTEL electronics) are used to measure the air velocity and rpm of the pinion respectively.

\section{RESULTS AND DISCUSSIONS}

\section{Manual Applied Force}

First, the experiments are carried out to generate power by manual force. Numbers of experiments are conducted with different stem height and different rack length. Different types of stems are used in this experiment like PVC pipe, tree stem, acrylic \& MS rod. Spring gauge is used to generate manual force by tying up it at the top end of the stem. The 13 inch or $33 \mathrm{~cm}$ rack length is divided into five sections. Before taking any readings, the desired rack length has been set. As there are two sets of rack and pinion of the experimental setup, therefore, readings are taken for the both Side-1 and Side- 2 . In the following sections the experimental results will show the power generation for different stem height and materials for both Side-1 and Side-2. It should be noted that the rack length is indicated as $L_{R}$ in this article. It should mention here that each reading of the experiments are taken multiple times and take the average value.

\section{PVC Pipe (Side-1)}

At first, PVC pipe with 0.5 inch or $1.25 \mathrm{~cm}$ outer diameter is used as a stem for five different heights ranging from 18 inch to 30 inch (46 cm to $76 \mathrm{~cm}$ ). Rack length varies from 2.6 inch to 13 inch $(6.6 \mathrm{~cm}$ to $33 \mathrm{~cm}$ ) for different applied manual force by spring gauge. In Figure 3 (a), it is observed that for the stem height of PVC pipe with 18 inch $(46 \mathrm{~cm})$ height, the produced power increases with the increase of applied manual force. It is also evident from the figure that the longer rack length leads to have more rpm and

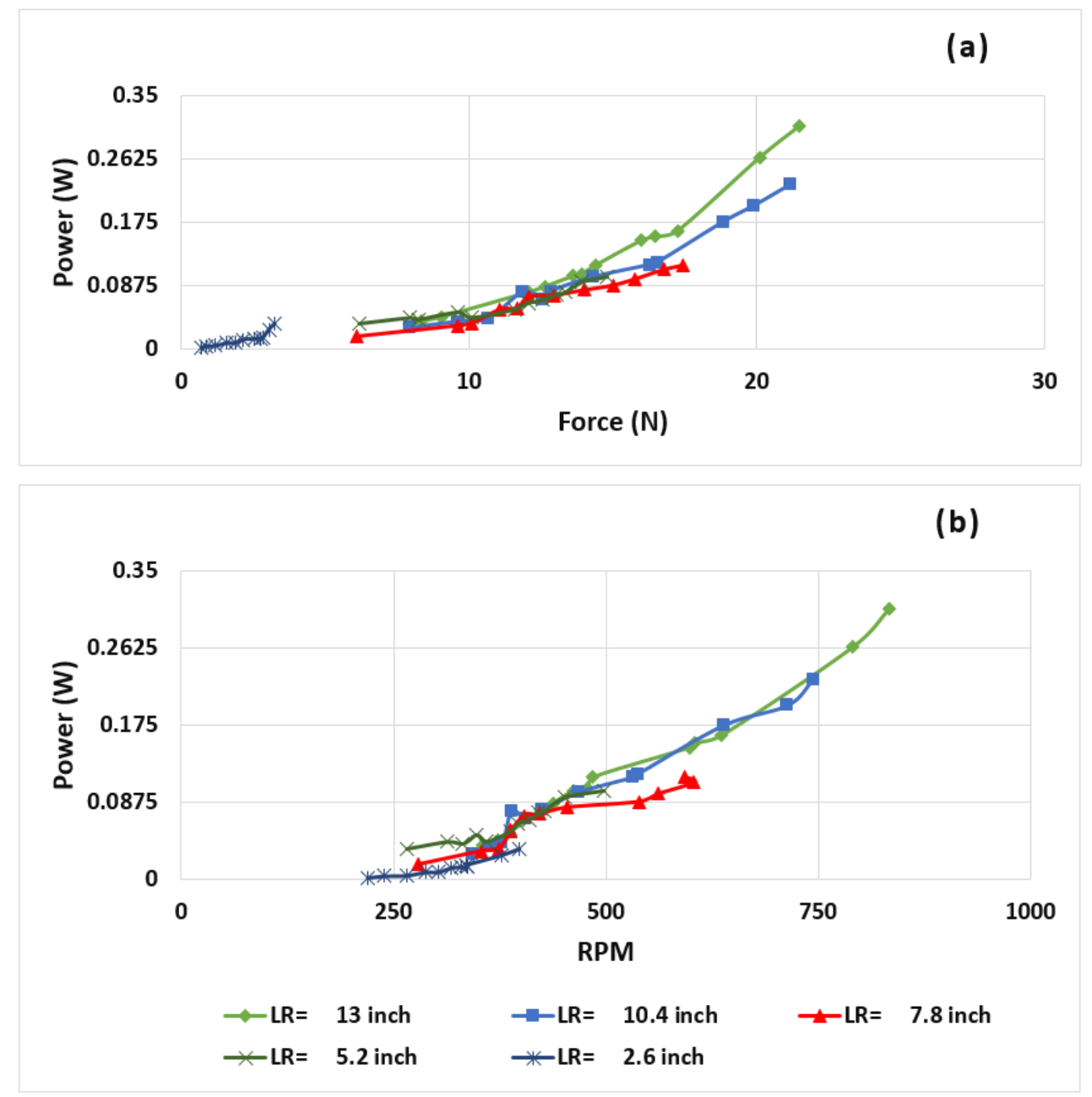

Figure 3. Power generation for PVC pipe at 18 inch height for different rack length in Side-1 for the variation of (a) force and (b) RPM 


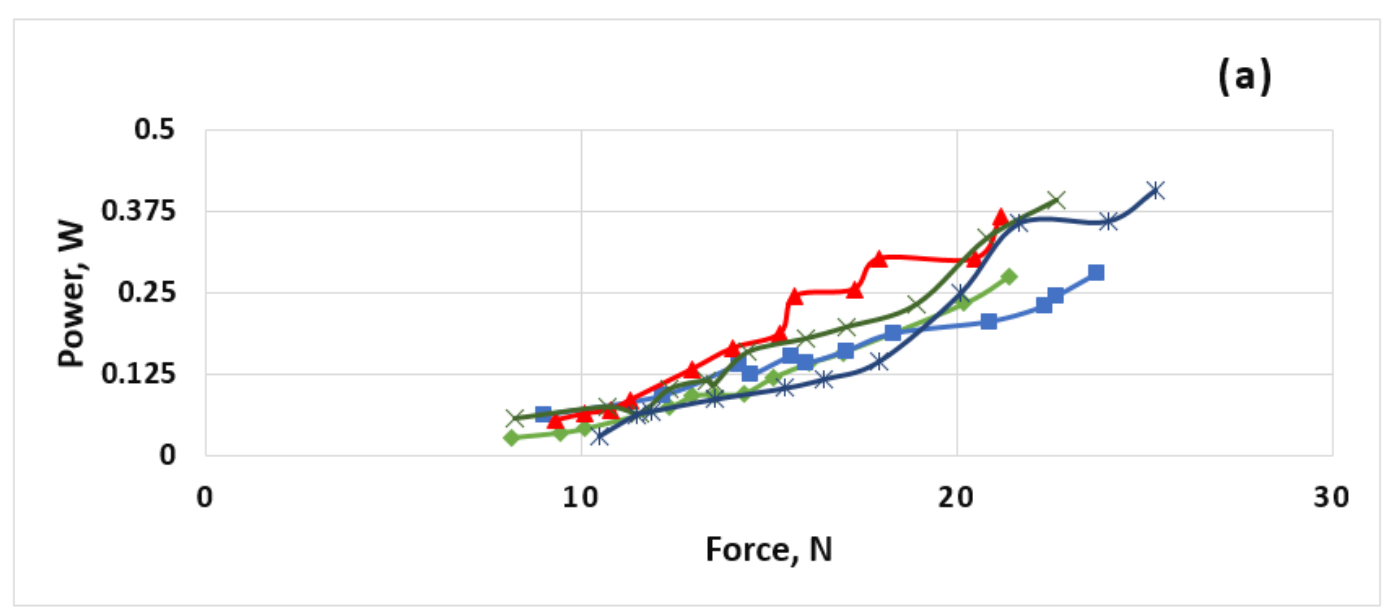

(b)

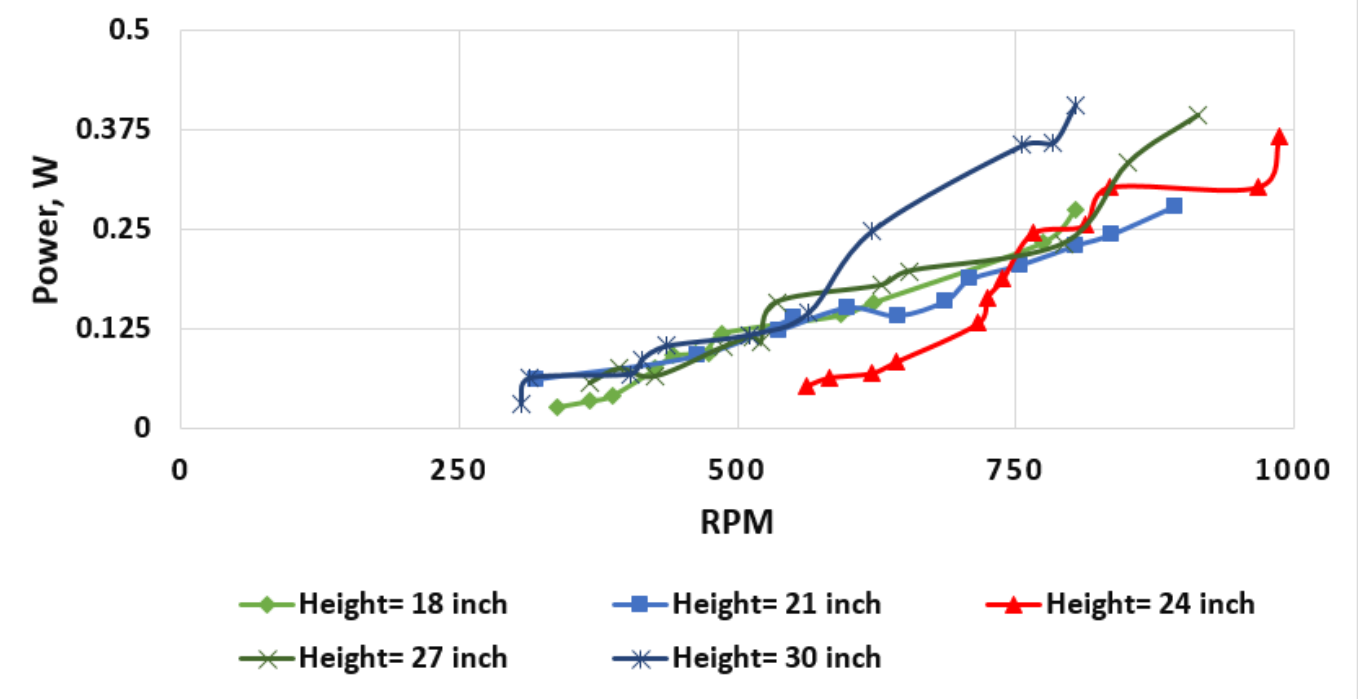

Figure 4. Power generation for PVC stem at different height for 13 inch rack length in Side-1 for the variation of (a) force, (b) RPM

hence the higher generated power. In fact, the power generation is much higher for the maximum rack length $\left(L_{R}=13 \mathrm{inch}(33 \mathrm{~cm})\right)$ because of travelling maximum distance which causes more rotation of the shaft. Inertia of motion among all the parts is also responsible for the increasing of power. Actually, once the higher manual force applied at one end of the stem causes more bend and leads to move far distance of the rack which means rack length increases. Therefore, pinion rotates more due to longer rack length movement and leads to generate more power which is clearly shown in Figure $\mathbf{3}$ (b). However, there is a lag between 2.6 inch $(6.6 \mathrm{~cm})$ rack length and other rack lengths. The reason behind is that the inertia of the rest among the connecting parts. Initially all the parts like wire, rack, pinion, shaft are at rest, therefore, once a certain amount of force is applied, generator does not get the exact force to rotate. The stem, connecting wire, rack, pinion utilize some force to move from their resting position. In addition, rotation of the pinion and generator shaft is very few in number because of the shortest rack length and causes to have the lowest power output. Therefore, a clear conclusion may draw from Figure 3 is that the increase of applied manual force leads to increase the rack length and leads to rotate the pinion at higher rpm and ultimately increases the power generation. From the experimental setup, it can also easily understand that rpm is totally dependent on applied force. The more force will create more $\mathrm{rpm}$, thus, the maximum rpm is for the longest rack length 13 inch and minimum for the shortest rack length 2.6 inch.So, the maximum rack length 13 inch is considered for rest of the experiment.

In Figure 4 (a) \& (b), five different heights 18, 21, 24, 27 \& 30 inch $(46,54,61,68 \& 76 \mathrm{~cm})$ of PVC pipe have been taken with the maximum rack length 13 inch. The value of power generation increases with the increase of height of the PVC stem. The results show that the lowest output from the minimum height of 18 inch of the PVC pipe and highest output from the maximum height 30 inch of the PVC pipe. The output power increases with the increase of the height of the stem which is due to the bending capability of the stem. As the height of the stem increases therefore, for certain applied manual force create more torque leads to do more work. In fact, with the evidence from Figure $\mathbf{4}$ (a) and (b) indicates that higher the stem length will be beneficial to produce more power and it also observed that power is increased with the increase of the force and as well as rpm. Anyway, 30 inch stem length is chosen for the rest of the experimental study.

From the Figure 5 (a) \& (b) show all the value of power generation from the five different heights of the PVC pipe by changing all the five rack lengths. By increasing the force and rpm, power generation is also increasing. Actually this figure shows the full scenario of the power generation for Side-1. 
(a)

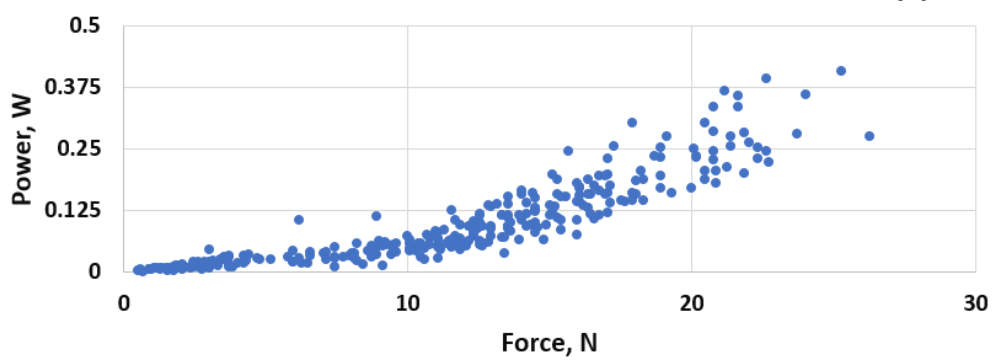

(b)

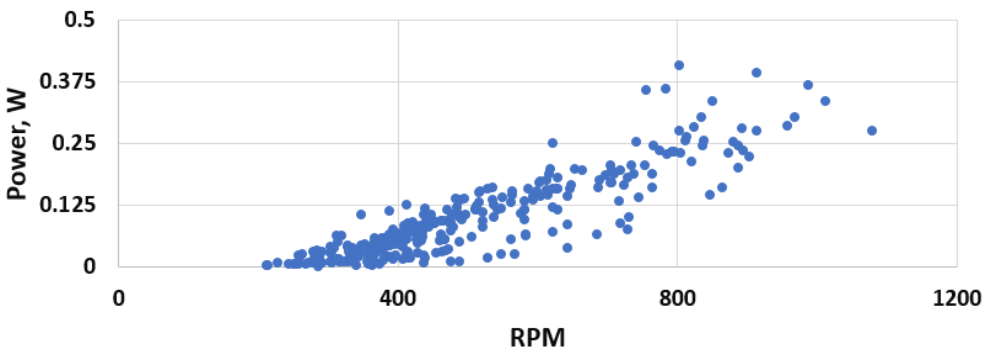

Figure 5. Full scenario of power generation for PVC stem at different height and rack length in Side-1 for the variation of (a) force and (b) RPM
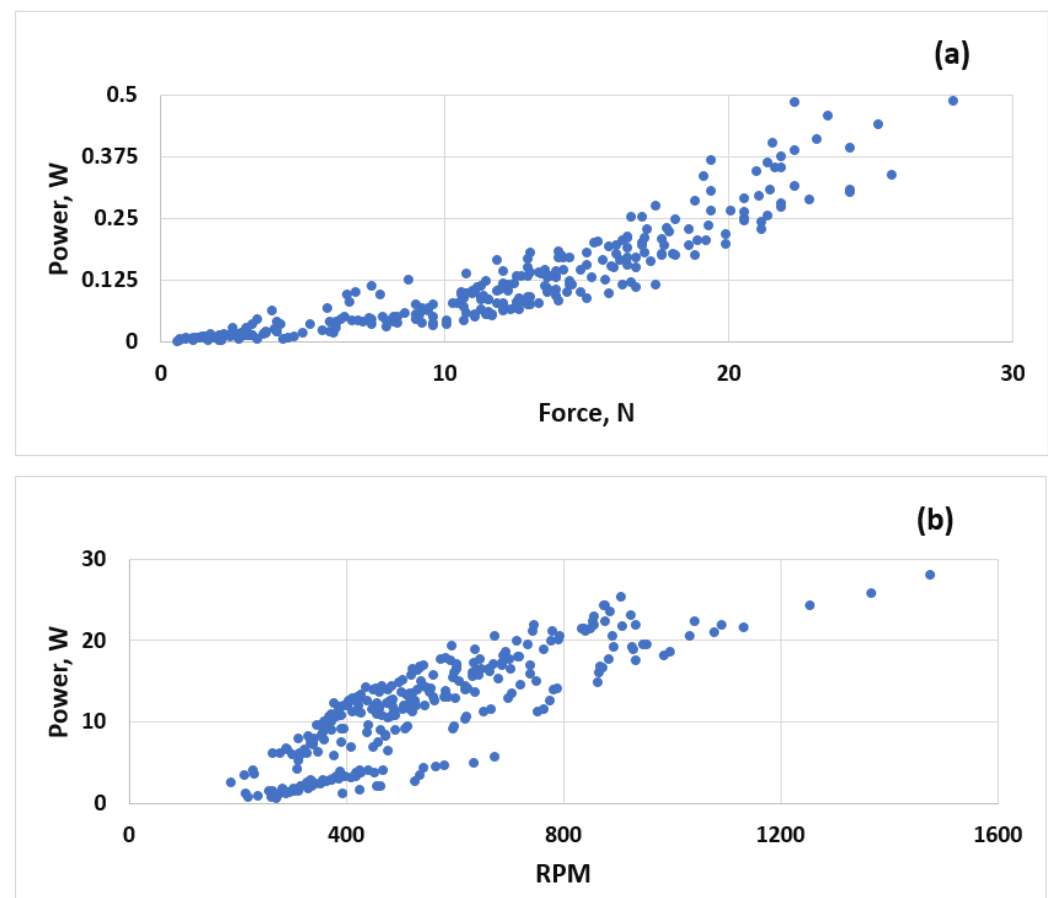

Figure 6. Full scenario of power generation for PVC stem at different height and rack length in Side-2 for the variation of (a) force and (b) RPM

\section{PVC Pipe (Side-2)}

Like Side-1, exactly same procedure has been followed for Side-2. Similarly, all the value of power generation from the five different heights of the PVC pipe by changing all the five different rack lengths has been shown for Side-2 in Figure 6 (a) \& (b). These two graphs reflect the whole nature of the power generation and its dependency on applied force, stem length and rack length for Side-2. In comparison with Figure 5 (a) \& (b), it is clearly seen that the power generation for Side-2 in Figure 6 (a) \& (b) is little higher than Side-1. There would be some reasons and frictional loss is one of them. In addition, the mesh of pinion and rack may not as smooth as Side-2. Bad pinion seal, resistance in wires, eddy current loss etc. are also responsible. Therefore, the rest of the experiments are conducted in Side-2 for 13 inch rack length and 30 inch stem height. 

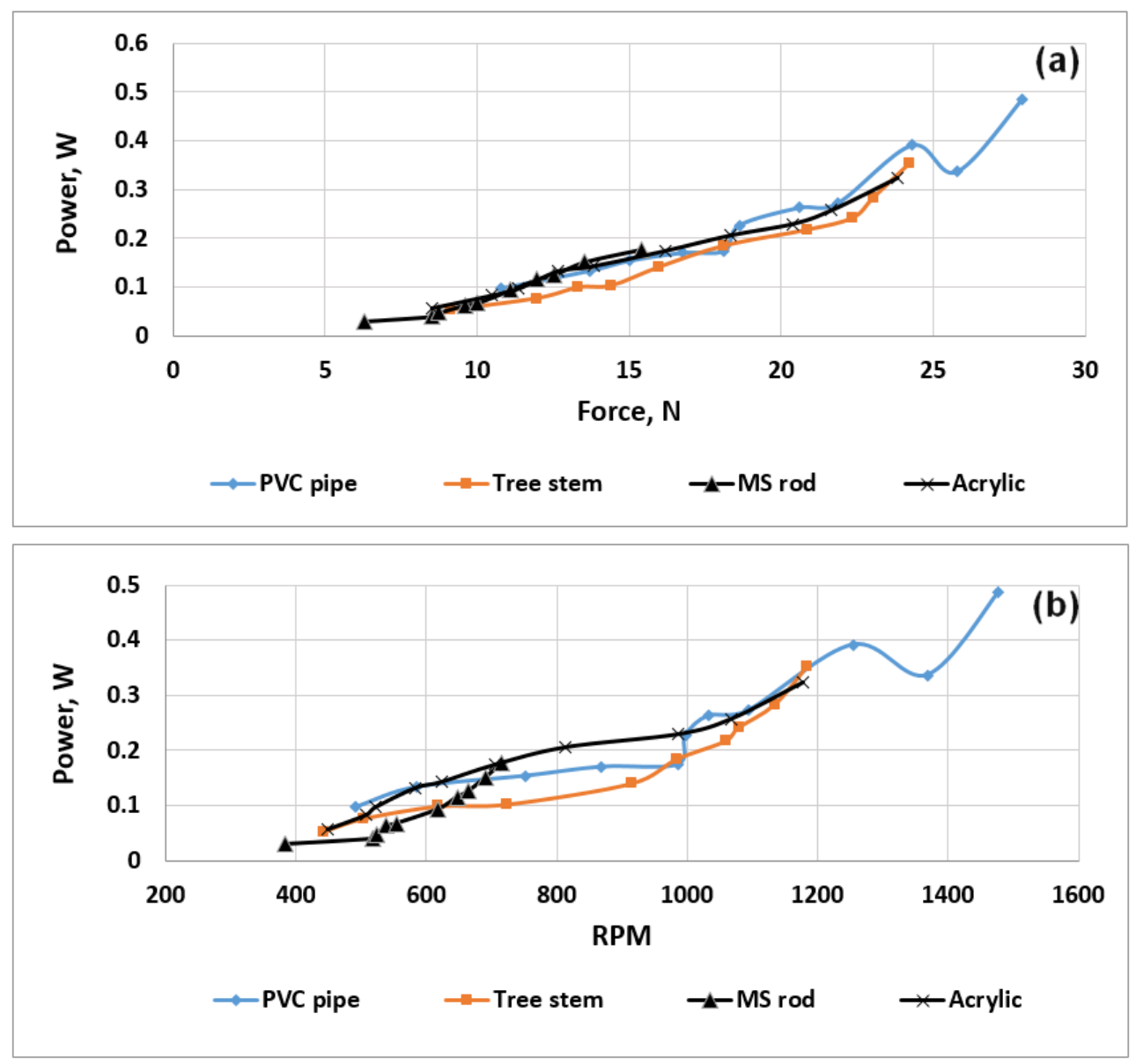

Figure 7. Comparison of power generation for different materials for Side-2 for the variation of (a) force and (b) RPM

Table 1. Flexural strength of different stem materials

\begin{tabular}{ll}
\hline Material & Flexural Strength \\
\hline PVC pipe & $88 \mathrm{MPa}[$ https://www.curbellplastics.com/Research-Solutions/] \\
\hline Tree stem & ------- \\
\hline Acrylic & $117 \mathrm{MPa}[$ https://www.curbellplastics.com/Research-Solutions/] \\
\hline MS rod & $2.76 \mathrm{GPa}[$ Nurulhuda et al 2017] \\
\hline
\end{tabular}

As explained earlier that the bending or displacement of the top end of the stem influences the power generation, therefore different yield and flexural strength of materials are considered for further experiments in power generation. Four different materials like PVC pipe, MS rod, acrylic and tree stem are chosen for this investigation. The outer diameter of tree stem, acrylic \& MS rod are $0.4,0.4$ and 0.5 inch $(1,1$ and $1.25 \mathrm{~cm})$ respectively. Figure 7 represents the power generation at Side- 2 for different stem materials with stem height of 30 inch and rack length of 13 inch. Figure 7 (a) \& (b) clearly show that PVC pipe has generated the maximum power among all the materials. In fact, the tree stem, acrylic \& MS rod has generated less power than PVC pipe. The flexural strength plays a major role in this issue and Table 1 shows the flexural strength of different stem material. Among all the specimens (stems), PVC pipe shows and makes a difference with other stem in power generation. Moreover, the PVC pipe has minimum flexural strength than other known materials as shown in Table 1. The tree stem is selected in this experiment for the sake of justification in practical application and use of wind energy even though flexural strength of tree stem is unknown. One of the major goals of the study is to investigate the feasibility to extract power by constructing a setup and use in the divider on the highways or any windy area where stem or similar object or structure oscillate or swing. The results from Figure 7 (a) and (b) indicate that using the tree stem could produce equivalent amount of power as MS rod, acrylic and PVC pipe generated. Moreover, using tree stem of a tree may reduce the cost of the power generation.

\section{Tested in Wind Tunnel}

As mentioned earlier that the goal of the present study was to generate power from wind energy, especially at the windy area where the wind flow direction is not certain. Therefore, a vertical stem may oscillate and produce power. In that point of view, further experiments are carried out by means of wind flow. In such case the setup is installed at the outside of the wind tunnel where wind flow is controlled. In addition, a sail is placed at the top end of the vertical stem to capture the wind force. Knowing the velocity of the wind, force on the sail can be calculated by Bernoulli's equation. Different height of the stem and different sail area has been used here. Similar to previous study, the experiments are carried out on Side-2 for 13 inch rack length. 
(a)

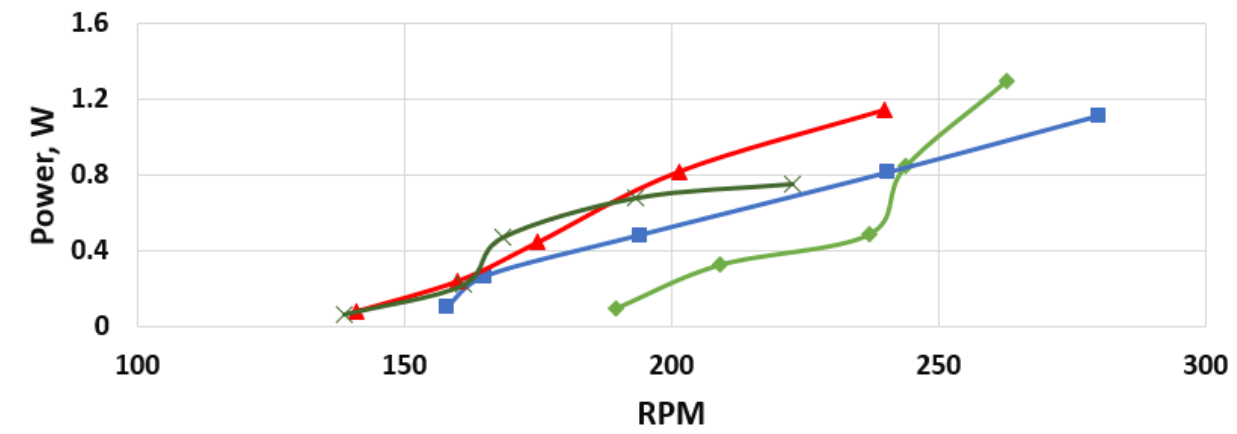

(b)
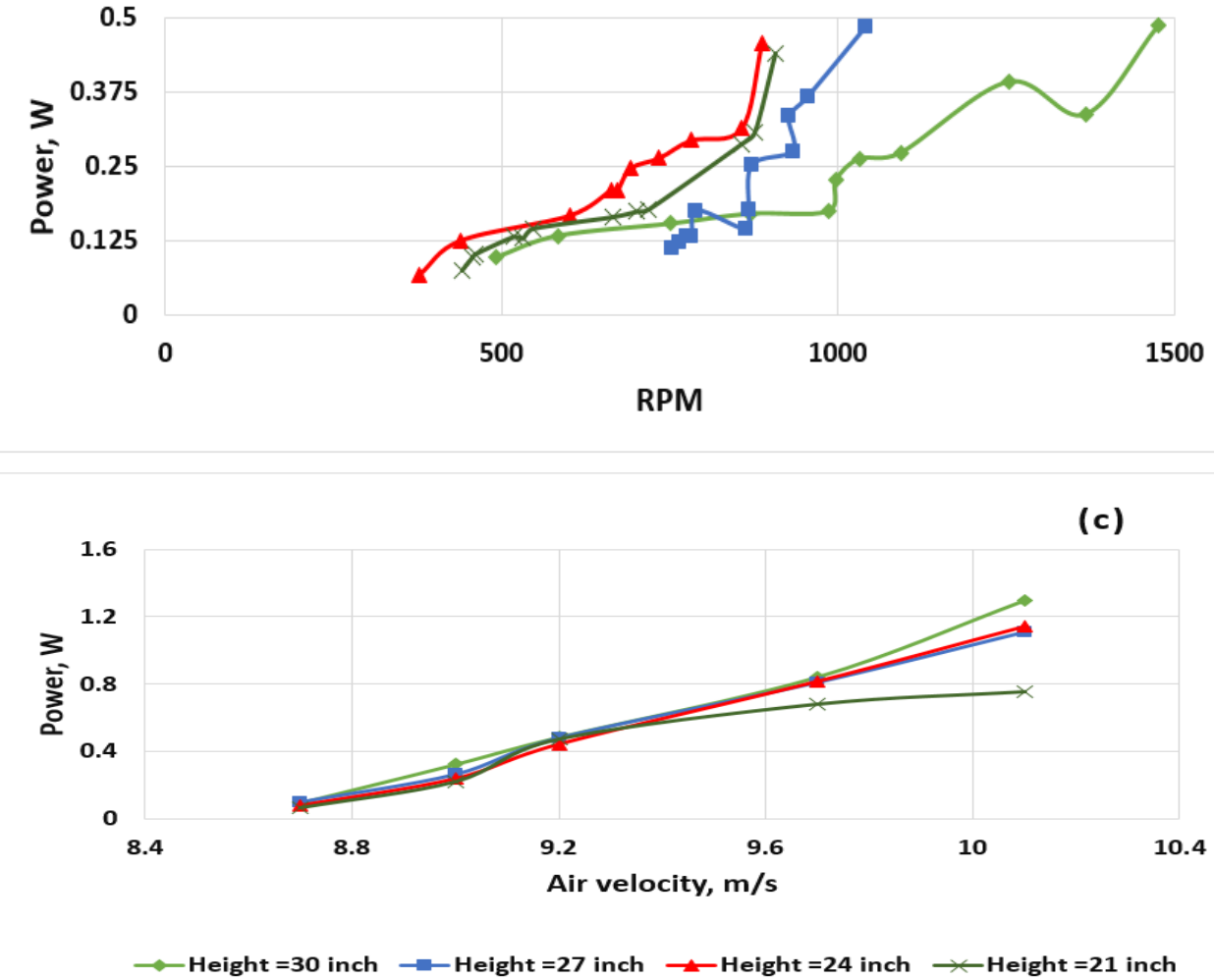

Figure 8. Power generation at different height for Side-2, (a) RPM for wind assist experiments, (b) RPM for manually applied force and (c) air velocity (wind assist experiments)

For the initial experiments the sail area is set as $238 \mathrm{inch}^{2}\left(1536 \mathrm{~cm}^{2}\right)$ and the stem and sail material are used as PVC pipe and cement bag (polypropylene) respectively and the stem height varies from 21 inch to 30 inch ( $54 \mathrm{~cm}$ to $76 \mathrm{~cm}$ ). Figure 8 (a) shows that the power generation increases with the increase of the stem height for different air velocities. The power generation is highest for the maximum height of the stem 30 inch $(76 \mathrm{~cm})$. Figure 8 (b) shows the power generation which has been obtained from the previous experiment i.e. manual applied force for different stem height at Side-2. It is evident from Figure $\mathbf{8}$ (a) and (b) that the value of power is much higher for air driven force experiment than the manually forced. There are many reasons for these higher values of the power, firstly, the sail area is much increased in wind assist experiment 238 inch $^{2}\left(1536 \mathrm{~cm}^{2}\right)$ for wind assist and 24 inch $^{2}\left(155 \mathrm{~cm}^{2}\right)$ for manual force test and helps to capture much air and hence the force on the sail. Secondly, the sail was flat and rigid in the previous experiment as the sail was made of MS sheet, however, in the wind assist experiments the sail materials are much flexible and have elasticity. Thirdly and most importantly, the force applied in manual case was not continuous, but in the wind assist case force applied continuously, in fact, once the stem bends in the downstream direction of the wind flow and wind pushes further the sail which may make advantageous of the setup to produce more power. Moreover, it should be noted here that the rpm for wind assist test much lower but continued for longer time, on other hand for manual applied force, rpm is higher but continued for short time and ultimately causes in the variation of power generation. Figure $\mathbf{8}$ (c) shows the generated power against wind speed for different stem height. It is evident from the results that the higher wind speed ensures higher power; moreover, stem height may give extra benefit in case of power generation for higher wind speed. 

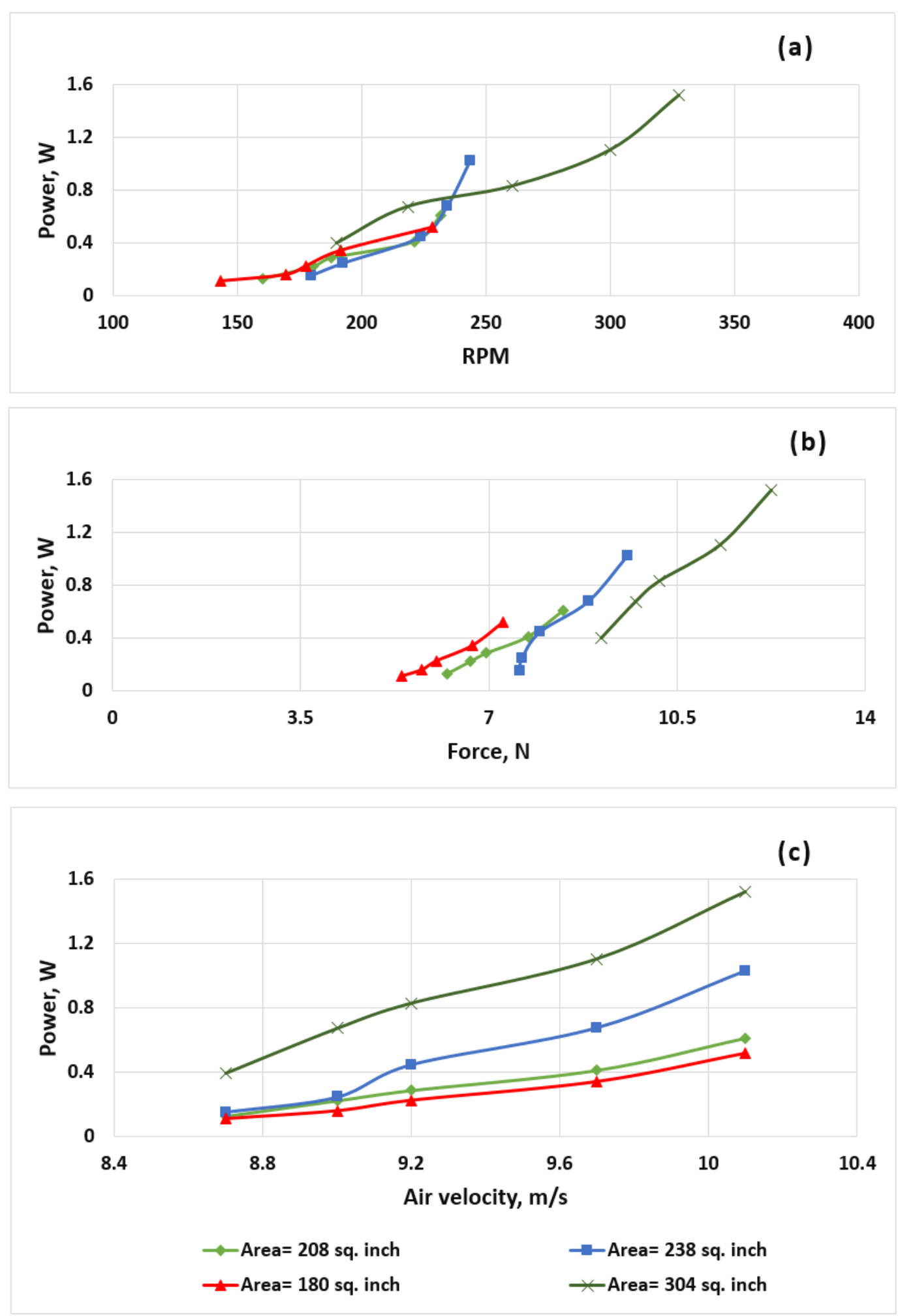

Figure 9. Power generation at different sail areafor Side-2, (a) RPM (wind assist experiment), (b) Force (manually applied force) and (c) air velocity (wind assist experiments)

Figure 9 shows the effect of sail area on power generation for the wind flow conditions. Four different sail area like 108, 208, 238 and 304 inch $^{2}\left(697,1342,1535\right.$ and $\left.1961 \mathrm{~cm}^{2}\right)$ are considered for this particular experiment. Figure 9 (a) and (b) show the power generation against the rpm and force. Force is here is calculated from Bernouilli's equation and indicated that increase the force or rpm increases the power and at the same time larger sail area exhibits more power. Similarly, increase the velocity of the wind also indicates the sameresults as before. However, the finding is that sail area is much more influential than the stem length for power generation. 

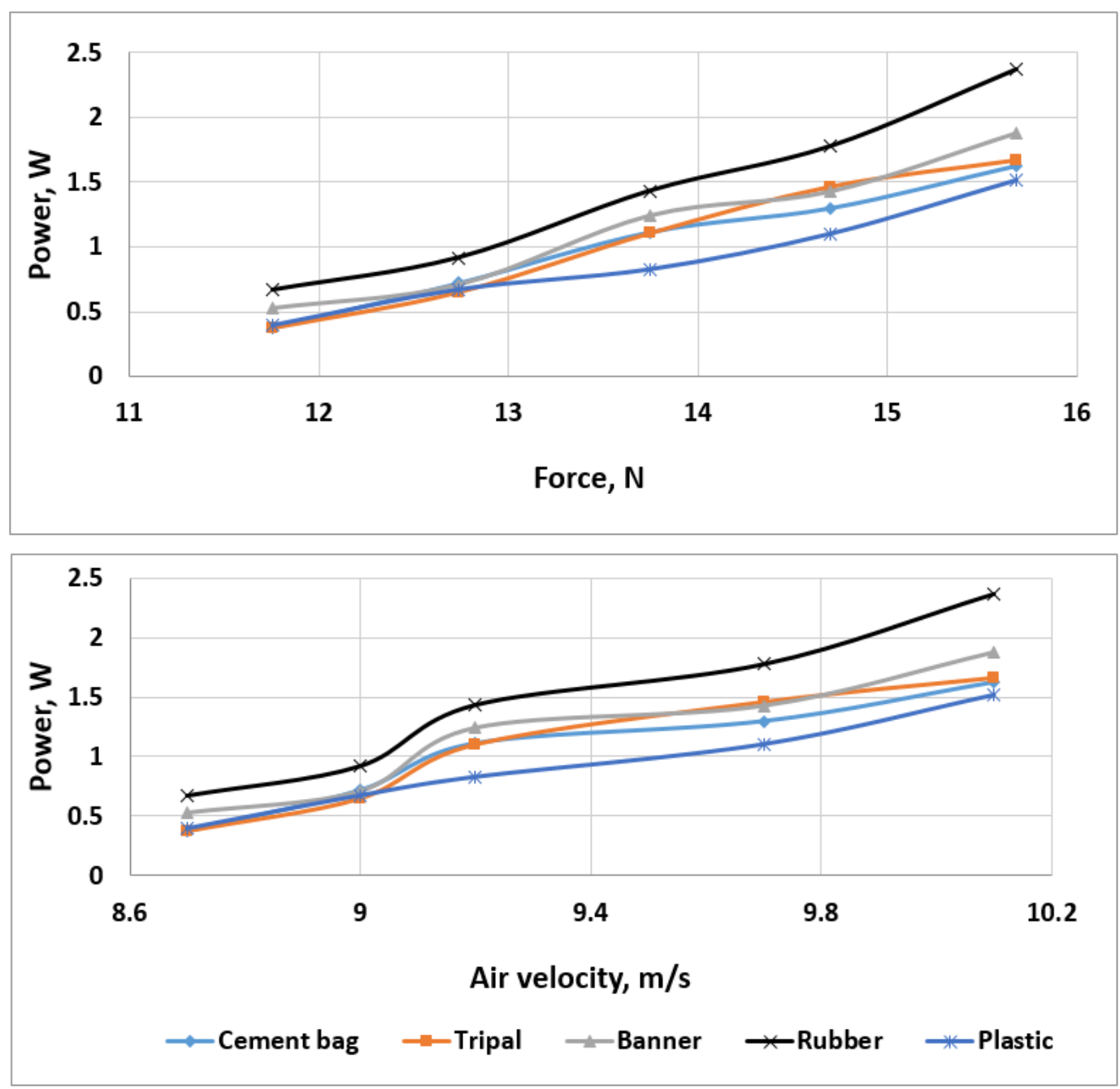

Figure 10. Power generation at different materials for Side-2 for wind assist experiments (a) force and (b) air velocity

Table 2. Density and flexural strength of different sail materials

\begin{tabular}{lcl}
\hline Material & Specific Gravity & Flexural Strength, MPa \\
\hline Rubber & $0.9 \sim 0.92$ & $135[\mathrm{https} / /$ www.toray.jp/plastics/en/torelina/technical/] \\
\hline Banner & 1.42 & $88[\mathrm{https://www.curbellplastics.com/Research-Solutions/]}$ \\
\hline Tripal & 0.95 & $28.3-91[\mathrm{http}: / /$ www.matweb.com/] [https://www.plasticsintl.com/datasheets/HDPE.pdf] \\
\hline Cement bag & 0.91 & $40[\mathrm{http://www.matweb.com/reference/flexuralstrength.aspx]}$ \\
\hline Plastic & 0.92 & $8.1[\mathrm{https://www.plasticsintl.com/datasheets/LDPE.pdf]}$ \\
\hline
\end{tabular}

For the practical application of such device for power generation is one of the key objectives of this study. With this context the study is extended with different materials for sail which are locally available. Five different sail materials like plastic i.e. normal polythene (low density polyethylene, LDPE), advertisement banner (PVC banner), cement bag (polypropylene), tyre rubber (elastomer) and terpal or tarpaulin (high density polyethylene, HDPE) are considered. The materials for sails are chosen based on the concept of flexural strength and density and Figure $\mathbf{1 0}$ shows that the power generation by using different sail materials. Rubber has generated the maximum power among all the materials. Density and flexural strength of the sail materials play major roles here. Once the wind hits the sail, the flexible sail deforms in the wind flow direction as a part of work done by the wind which ultimately insist more wind to hit the sail. At the same time, with the deformation and the movement of the sail in the wind flow direction leads the density to play its part to move the sail and stem further downward. In fact, once the stem is tilted due to wind force the dense or heavy material of the sail gain further momentum and push further to bend the stem. The involvement of these two properties i.e. density and flexural strength are clearly visible in Figure 10. It should clearly state here that the volume (i.e. thickness) of the tyre rubber is much more as compared with the normal polyethylene i.e. plastic or other sail materials. The density and flexural strength of the different sail materials are shown in Table $\mathbf{2}$. Therefore, gravitational force along with density also plays a vital role to produce higher power.

The study has been carried out with the concept to harvest energy from tree due to wind flow. The constructed setup enables to generate power due to the bending of the stem. Considering the tree, gusty wind assists to bend the stem of a tree and therefore, the bending moment of the tree is important. Niklas (2002a) showed that the bending moment of the tree stem depends on the tree height and age. He carried out experimental study on cherry tree (Prunusserotina Ehrh.) for different height ranging from 0.95 
$\mathrm{ft}$ to $43 \mathrm{ft}(29 \mathrm{~cm}$ to $1310 \mathrm{~cm})$ and showed that smaller stems had higher stress capabilities due to flexible plant tissue than larger stems. He also added that older tree had higher probability of mechanical damage or fail as compared with the younger trees. He also showed that the bending moment of tree stem could be up to $3 \mathrm{MPa}$ for the wind velocity of $50 \mathrm{~m} / \mathrm{s}$ (Niklas $2002 \mathrm{~b}$ ). He also reported that the drag induced bending moment generated due to the presence of the branch at the point where they are attached near the trunk. Therefore, the roadside trees which are comparatively small in size in height may be expected as potential energy source to harvest energy from wind. In a normal day, the wind velocity may not sufficient enough to bend to stems or trees, however, once a vehicle moves at high speed creates vortices and generates two distinct regions. A weak wind region at the downstream directly at the rear of the vehicle and other one is a strong wind region at the downstream side surface of the vehicles (Tian et al., 2017). This strong wind velocity may increase up to $30 \mathrm{~m} / \mathrm{s}$ and produce significant amount energy with the rotation of the rotor blade. Therefore, the strong wind region produces a gust and able to bend the tree depending on the vehicle speed, tree size and age and the distance of the tree from the moving vehicle. However, any other object or structure around us may also consider for the particular purpose. In the urban area the oscillating bodies or structures can be placed to harvest the energy where the wind velocities are relatively higher. Recently, Stathopoulos et al. (2018) and Micallef and Bussel (2018) showed that the suitable places for the devices to install in the urban areas and harvest the energy from the wind.

\section{CONCLUSIONS}

An experimental setup is constructed to harvest energy from wind by the means of oscillating the body or structure or even trees. The experiments are carried out for two different modes of applied force on stem i.e. manual force and wind assist force. The overall experimental results showed that the stem length, rack length, forces applied on the sail is the vital issue to increase the generated power. However, wind assist force reveals that sail area and materials of the sail and stem play major role on power generation. Considering the tree stem along with other stem of different materials showed that tree stem can be easily used in the constructed setup and able to produce similar amount of energy as compared with other stem materials. The conceptual design may be further improved with the numbers rack and pinion mechanisms, $360^{\circ}$ rotation of the sail while the tree stem is fixed. If the top of the sail is heavier than its root, it will create more momentum while it hits by wind. Thus, it will generate power uninterruptedly with the zero safety hazards. An optimum model considering the height and material of the stem and the area of the sail and its material can make a difference to the renewable energy industry. Small and light scale of the setup along with the less frictional resistance among the moving parts can be installed at the roadside of a highway or any other windy area to extract energy from wind as there are thousands of kilometer roads around the world and millions of vehicles move each day.

\section{REFERENCES}

Ahmed, R., Mir, F. and Banerjee, S. (2017). A review on energy harvesting approaches for renewable energies from ambient vibrations and acoustic waves using piezoelectricity. Smart Mater. Struct., 26, 085031. https://doi.org/10.1088/1361$665 \mathrm{X} / \mathrm{aa} 7 \mathrm{bfb}$

Blocken, B. and Stathopoulos, T. (2013). CFD simulation of pedestrian-level wind conditions around buildings: Past achievements and prospects. Journal of Wind Engineering and Industrial Aerodynamics, 121, 138-145. https://doi.org/10.1016/j.jweia.2013.08.008

Blocken, B., Stathopoulos, T. and van Beeck, J. P. A. J. (2016). Pedestrian-level wind conditions around buildings: Review of windtunnel and CFD techniques and their accuracy for wind comfort assessment. Building and Environment, $100,50-81$. https://doi.org/10.1016/j.buildenv.2016.02.004

Deane, J. P., Gallachóir, B. P. Ó. and McKeogh. E. J. (2010). Techno-economic review of existing and new pumped hydro energy storage plant. Renewable and Sustainable Energy Reviews, 14(4), 1293-1302. https://doi.org/10.1016/j.rser.2009.11.015

Flexural Strength Testing of Plastics. (n.d.). Available at: http://www.matweb.com/reference/flexuralstrength.aspx (Accessed 11 March 2019).

Glumac, A. S., Hemida, H. and Höffer, R. (2018). Wind energy potential above a high-rise building influenced by neighboring buildings: An experimental investigation. Journal of Wind Engineering and Industrial Aerodynamics, $175,32-42$. https://doi.org/10.1016/j.jweia.2018.01.022

Han, M. Y., Han, M. Y., Sui, X., Huang, Z. L., Wu, X. D., Xia, X. H., Hayat, T. and Alsaedi, A. (2014).Bibliometric indicators for sustainable hydropower development. Ecological Indicators, 47, 231-238. https://doi.org/10.1016/j.ecolind.2014.01.035

Howell, R., Qin, N., Edwards, J. and Durrani, N. (2010). Wind tunnel and numerical study of a small vertical axis wind turbine. Renewable Energy, 35(2), 412-422. https://doi.org/10.1016/j.renene.2009.07.025

https://www.plasticsintl.com/datasheets/HDPE.pdf (Accessed 11 March 2019).

https://www.plasticsintl.com/datasheets/LDPE.pdf (Accessed 11 March 2019).

Khalid, S., Raouf, I., Khan, A., Kim, N. and Kim, H. S. (2019). A Review of Human Powered Energy Harvesting for Smart Electronics: Recent Progress and Challenges. International Journal of Precision Engineering and Manufacturing-Green Technology, 6, 821851. https://doi.org/10.1007/s40684-019-00144-y

Kumar, D. and Katoch, S. S. (2014). Sustainability indicators for run of the river (RoR) hydropower projects in hydro rich regions of India. Renewable and Sustainable Energy Reviews, 35, 101-108. https://doi.org/10.1016/j.rser.2014.03.048 
Lehner, B., Czisch, G. and Vassolo, S. (2005). The impact of global change on the hydropower potential of Europe: a model-based analysis. Energy Policy, 33(7), 839-855. https://doi.org/10.1016/j.enpol.2003.10.018

Lewis, J. I. (2007). Technology Acquisition and Innovation in the Developing World: Wind Turbine Development in China and India. Studies in Comparative International Development, 42(3-4), 208-232. https://doi.org/10.1007/s12116-007-9012-6

Li, H., Tian, C. and Deng, Z. D. (2014). Energy harvesting from low frequency applications using piezoelectric materials. Applied Physics Reviews, 1, 041301. https://doi.org/10.1063/1.4900845

Li, S., Yuan, J. and Lipson, H. (2014). Ambient wind energy harvesting using cross-flow fluttering. Journal of Applied Physics, 109(2), 026104. https://doi.org/10.1063/1.3525045

Mak, K. H., McWilliam, S. and Popov, A. A. (2013). Piezoelectric energy harvesting for tyre pressure measurement applications. Proceedings of the Institution of Mechanical Engineers Part D Journal of Automobile Engineering, 227(6), 842-852. https://doi.org/10.1177/0954407012463849

MatWeb. Material Property Data. Available at: http://www.matweb.com/search/datasheet.aspx?matguid= 482765fad3b443169ec28fb6f9606660\&ckck=1 (Accessed 11 March 2019).

McCloskey, M. A., Mosher, C. L. and Henderson, E. R. (2017). Wind Energy Conversion by Plant- Inspired Designs. PLoS ONE, 12(1), e0170022. https://doi.org/10.1371/journal.pone.0170022

McGarry, S. and Knight, C. (2011). The Potential for Harvesting Energy from the Movement of Trees. Sensors, 11, 9275-9299. https://doi.org/10.3390/s111009275

McGarry, S. and Knight, C. (2012). Development and Successful Application of a Tree Movement Energy Harvesting Device, to Power a Wireless Sensor Node. Sensors, 12, 12110-12125. https://doi.org/10.3390/s120912110

Micallef, D. and Bussel, G. D. (2018). A Review of Urban Wind Energy Research: Aerodynamics and Other Challenges. Energies, 11, 2204. https://doi.org/10.3390/en11092204

Molarius, R., Keränen, J., Schabel, J. and Wessberg, N. (2010). Creating a climate change risk assessment procedure: Hydropower plant case, Finland. Hydrology Research An International Journal, 41(3-4), 282-294. https://doi.org/10.2166/nh.2010.123

Niklas, K. J. (2002a). Wind, size, and tree safety. Journal of Arboriculture, 28(2), 84-93.

Niklas, K. J. (2002b). Computing factors of safety against wind-induced tree stem damage. Journal of Experimental Botany, 51(345), 797-806. https://doi.org/10.1093/jexbot/51.345.797

Nurulhuda, A., Hafizzal, Y., Izzuddin, M. Z. M., Sulawati, M. R. N., Rafidah, A., Suhaila, Y. and Fauziah, A. R. (2017). Analysis on Flexural Strength of A36 Mild Steel by Design of Experiment (DOE). IOP Conf. Series: Materials Science and Engineering, $226,012153$. https://doi.org/10.1088/1757-899X/226/1/012153

Oh, S. J., Han, H. J., Han, S. B., Lee J. Y. and Chun, W. G. (2010). Development of a tree-shaped wind power system using piezoelectric materials. International Journal of Energy Research, 34, 431-437. https://doi.org/10.1002/er.1644

Plastic Properties Table (n.d.). Available at: https://www.curbellplastics.com/Research-Solutions/Plastic-Properties/ (Accessed 11 March 2019).

Qiu, J. and Ji. H. (2011). Research on applications of piezoelectric materials in smart structures. Frontiers of Mechanical Engineering, 6(1), 99-117. https://doi.org/10.1007/s11465-011-0212-4

Quinn, A. D., Baker, C. J. and Wright, N. G. (2001). Wind and vehicle induced forces on flat plates-Part 1: wind induced force. Journal of Wind Engineering and Industrial Aerodynamics, 89(9), 817-829.

Rajiv (2017). RF based wireless energy harvesting and its applications. Available at: https://www.rfpage.com/rf-based-wirelessenergy-harvesting-applications/ (Accessed 23 April 2019).

Ricci, M., Patruno, L., Kalkman, I., de Miranda, S. and Blocken, B. (2018). Towards LES as a design tool: Wind loads assessment on a high-risebuilding, Journal of Wind Engineering and Industrial Aerodynamics, 180, 1-18. https://doi.org/10.1016/j.jweia.2018.07.009

Sheng, R., Perret, L., Calmet, I., Demouge, F. and Guilhot, J. (2018). Wind tunnel study of wind effects on a high-risebuilding at a scale of 1:300. Journal of Wind Engineering and Industrial Aerodynamics, 174, $391-403$. https://doi.org/10.1016/j.jweia.2018.01.017

Solar Research, NREL. (n.d.) Available at: https://www.nrel.gov/solar/ (Accessed 11 June 2019).

Souza, C. P., Carvalho, F. B. S., Silva, F. A. N., Andrade, H. A., Silva, N. de. V., Baiocchi, O. and Müller, I. (2016). On Harvesting Energy from Tree Trunks for Environmental Monitoring. International Journal of Distributed Sensor Networks, 12(6), 9383765. https://doi.org/10.1155/2016/9383765

Stathopoulos, T. (1985). Wind environmental conditions around tall buildings with chamfered corners. Journal of Wind Engineering and Industrial Aerodynamics, 21(1), 71-87. https://doi.org/10.1016/0167-6105(85)90034-0

Stathopoulos, T., Alrawashdeh, H., Al-Quraan, A., Blocken, B., Dilimulati, A., Paraschivoiu, M. and Pilay, P. (2018). Urban wind energy: Some views on potential and challenges. Journal of Wind Engineering and Industrial Aerodynamics, 179, $146-157$. https://doi.org/10.1016/j.jweia.2018.05.018

Strom, B., Brunton, S. L. and Polagye. B. (2017). Intracycle angular velocity control of cross-flow turbines. Nature Energy, $2,17103$. https://doi.org/10.1038/nenergy.2017.103

The Future of Solar Energy. (n.d.). Available at: http://energy.mit.edu/research/future-solar-energy/ (Accessed 9 June 2019). 
The Realities of RF Power Harvesting (2015). Available at: https://www.arrow.com/en/research-and-events/articles/the-realitiesof-rf-power-harvesting/ (Accessed 24 April 2019).

Tian, W., Mao, Z., An, X., Zhang, B. and Wen, H. (2017). Numerical study of energy recovery from the wakes of moving vehicles on highways by using a vertical axis wind turbine. Energy, 141, 715-728. https://doi.org/10.1016/j.energy.2017.07.172

Toray Plastics. (n.d.). Technical Information | MechanicalProperties | Flexural Properties. Available at: https://www.toray.jp/plastics/en/torelina/technical/tec_006.html (Accessed 11 March 2019).

Xu, D., Huang, S., Lei, Q. and Cheng. X. (2012). Preparation, properties and application research of piezoelectric traffic sensors. Procedia Engineering, 27, 269-280. https://doi.org/10.1016/j.proeng.2011.12.453

Xu, W., Wong, M.-C. and Hao, J. (2019). Strategies and progress on improving robustness and reliability of triboelectric nanogenerators. Nano Energy, 55, 203-215. https://doi.org/10.1016/j.nanoen.2018.10.073

Xu, Y. and Feng, D. (2012). The Study of Bioelectricity on the Trees and Their Applications as Power Sources. Asia-Pacific Power and Energy Engineering Conference, Shanghai, China, 27-29 March 2012. https://doi.org/10.1109/APPEEC.2012.6306957

Zhang, G., Chen, V., Xu, W., Galos, R., Zhou, L. and Shi, Y. (2014). Piezoelectric leaf generator for wind energy harvest. ASME Proceedings | 8th International Conference on Micro- and Nanosystems, Paper No. DETC2014-35417, pp. V004T09A031; 4 pages, From: ASME 2014 International Design Engineering Technical Conferences and Computers and Information in Engineering Conference. https://doi.org/10.1115/DETC2014-35417

Zheng, C., Xie, Y., Khan, M., Wu, Y. and Liu, J. (2018). Wind-induced responses of tallbuildings under combined aerodynamic control. Engineering Structures, 175, 86-100. https://doi.org/10.1016/j.engstruct.2018.08.031

Zhou, Q., Lee, K., Kim, K. N., Park, J. G., Pan, J., Bae, J., Baik, J. M. and Kim, T. (2019). High humidity- and contamination-resistant triboelectric nanogenerator with superhydrophobic interface. Nano Energy, 57, 903-910. https://doi.org/10.1016/j.nanoen.2018.12.091 